\title{
Investigation of the dynamic characteristics of suspension parameters on a vehicle experiencing steering drift during braking
}

N Mirza $^{1}$, K Hussain ${ }^{1 *}$, A J Day ${ }^{1}$, and J Klaps ${ }^{2}$

${ }^{1}$ School of Engineering, Design and Technology, University of Bradford, Bradford, UK

${ }^{2}$ Ford Motor Company, Genk, Belgium

The manuscript was received on 7 January 2005 and was accepted after revision for publication on 22 July 2005.

DOI: 10.1243/095440705X35017

\begin{abstract}
This paper presents a simulation study into the characteristics of a vehicle experiencing steering drift under straight line braking. Simulation modelling has been performed using a multi-body dynamics analysis based on a model of an actual vehicle. Front and rear suspension parameters have been modelled as rigid links joined with flexible bushes so as to assess their effect on a vehicle while braking. Suspension geometry and alignment settings, which define characteristic responses such as lateral acceleration, yaw velocity, toe, and caster angles of a vehicle in a transient manoeuvre, are primary to a vehicle's directional stability. Any symmetric inconsistencies in these settings will potentially affect a vehicle's performance. The findings from this research have increased the understanding of the causes of steering drift during braking conditions.
\end{abstract}

Keywords: vehicle, dynamics, multi-body, modelling, drift, handling, braking, suspension

\section{INTRODUCTION}

Vehicle dynamic design, analysis, and testing have improved significantly in recent years. Multi-body dynamic (MBD) CAE tools such as ADAMS [1] have enabled the construction and analysis of realistic simulations in a much reduced time. Virtual prototyping has made research and development more cost-effective, simulating real effects such as high and low frequency inputs, effect of suspension bushes, and loads from road surfaces, bumps and potholes, cornering, and braking.

The dynamic performance of a vehicle is primarily influenced by the detail of the vehicle design, tyre and suspension characteristics, and the operating conditions. One area of dynamic performance which has become increasingly important to customers is steering drift during braking [2]. This is an undesirable condition where the driver is required to

\footnotetext{
* Corresponding author: School of Engineering, Design and Technology, University of Bradford, Richmond Road, Bradford BD7 1DP, UK. email: k.hussain1@bradford.ac.uk
}

apply a constant correction torque on the steering wheel during even the lightest braking, in order to keep the vehicle to the intended path. Steering drift in general has several different categories, ranging from a steady drift in one direction, a drift which only occurs after turning (also known as memory steer), or one which only occurs under certain driving conditions such as bump steer or torque steer. The term 'drift' means to wander to one side or the other.

Experimental investigations by Klaps and Day [3] have identified factors that influence conditions of steering drift in a passenger car (with or without braking) which will be verified in this paper using simulation study. These factors include:

(a) uneven side-to-side camber, which can cause a vehicle to drift towards the side with the most (positive) camber as compared to the side that has the least (negative) camber;

(b) uneven side-to-side caster, which can make a vehicle drift towards the side that has the least (negative) caster; 
(c) uneven toe angles or misalignment of the front wheel toe angles, which can cause drift to either side as well as a general directional vagueness;

(d) rear axle steer, which can be generated by misalignment of the rear wheels, e.g. incorrect rear toe settings;

(e) low tyre pressure, which can cause the vehicle to drift towards the side with low tyre pressure, especially if this is a front wheel;

(f) mismatched tyres side-to-side, which can cause the vehicle to drift towards the side with greater rolling resistance;

(g) uneven tyre wear, which, when tread wear develops conicity, gives the same effect as camber, causing the tyre to roll towards the side which is more worn; and

(h) plysteer, which arises from a manufacturing defect in the way the belts are positioned inside the tyre, causing the generation of a lateral force as the tyre rolls.

(i) 'Drift' is a lower intensity deviation from the intended line of travel. 'Pull' is a higher intensity deviation, and if a vehicle pulls to one side during braking, the first possible explanation coming to mind is different brake force between left and right front wheels. The application of vehicle brakes generates forces, which can be unequal owing to the variation of friction, pressure, temperature, tyre adhesion, weight transfer, and vehicle speed. The variation of these braking forces can be an influencing factor in brake pull, but such variation is seldom found nowadays on a well-maintained vehicle.

This paper presents a simulation study of steering drift during braking and investigates the possible causes of steering drift in a vehicle during straightline braking. The results from the simulation study have been compared and the trends have been verified with experimental data from published work
$[3,4]$. Furthermore, sensitivity analyses have been carried out to assess the effect of suspension parameter variation on the vehicle drift characteristics.

\section{VEHICLE MODEL}

A vehicle simulation model was constructed using ADAMS/CHASSIS commercial software, comprising a McPherson-type suspension system, Ackerman steering system, tyres, drive, and brake system. The model is shown in Fig. 1 and the component parts are listed in Table 1.

Model parameters were taken from manufacturer's data as indicated in Table 2 and which defines the front suspension geometry and the alignment settings of the vehicle. The data refers to the unladen condition, i.e. without the driver and under static conditions.

\section{RESULTS AND DISCUSSION}

The vehicle model was set to drive at a test speed of $100 \mathrm{~km} / \mathrm{h}$ in a straight line. Braking was then applied after $2 \mathrm{~s}$ with a deceleration of $0.7 \mathrm{~g}$ until it came to rest. The proportion of braking force applied to the front and rear wheels was $80 / 20$ and brake balance was equal on each side. Two steering constraints were employed: free and fixed control. Under free control, the steering wheel was not held during braking (zero applied torque, non-zero steering wheel angle), while for the fixed control, the steering wheel was kept fixed at a zero angle (non-zero applied torque).

Figure 2(a) shows the predicted vehicle velocity and longitudinal deceleration, while Fig. 2(b) shows the steering wheel angle and the torque's time history

Table 1 Model components description

\begin{tabular}{ll}
\hline Index number & Component description \\
\hline 1 & Telescopic strut modelled with top mount bushing and coil spring \\
2 & Lower control arm rear vertical bushing $(x / y$ direction - radial, $z$ direction axial) \\
3 & Lower control arm front vertical bushing ( $x / y$ direction - radial, $z$ direction axial) \\
4 & Lower control arm (LCA) \\
5 & Rack and pinion steering system \\
6 & Tyres fitted with standard pacejka data \\
7 & Subframe - front bushings (rigid subframe) \\
8 & Subframe - rear bushings (rigid subframe) \\
9 & Tie rods or track rods \\
10 & Stabilizer bar \\
11 & Lower ball joint \\
12 & Spindle \\
\hline
\end{tabular}




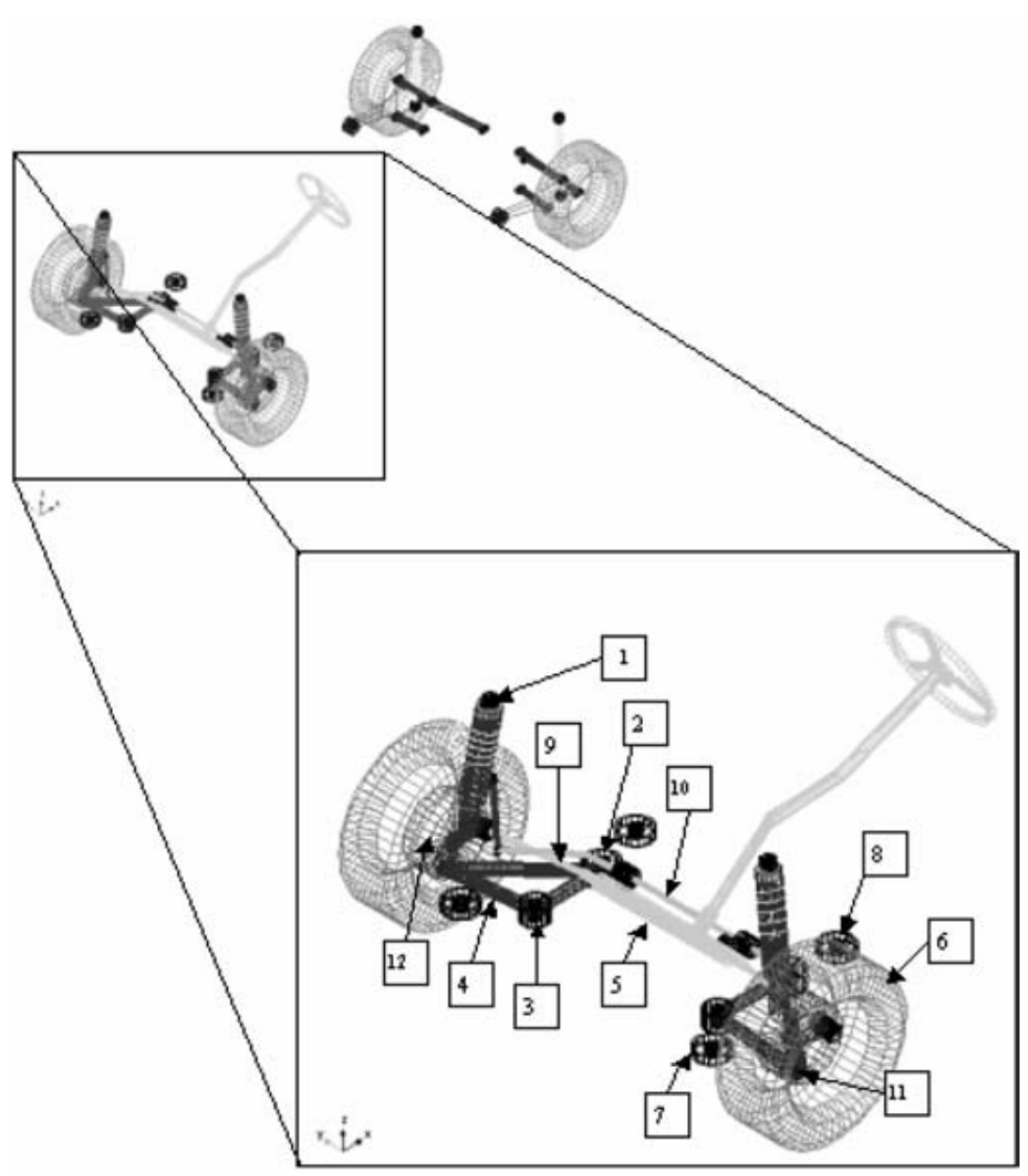

Fig. 1 Vehicle model

Table 2 Static vehicle characteristics (SVC)

\begin{tabular}{|c|c|c|c|c|c|c|}
\hline Description & \multicolumn{3}{|c|}{ Original vehicle ${ }^{[2]}$} & \multicolumn{3}{|c|}{ Simulated model } \\
\hline \multicolumn{7}{|c|}{ Mass properties } \\
\hline CG location & $\mathrm{X}$ & $\mathrm{Y}$ & $\mathrm{Z}$ & $\mathrm{X}$ & $\mathrm{Y}$ & \\
\hline & - & & - & 2800 & & 712 \\
\hline CG height (mm) & \multicolumn{3}{|c|}{500} & \multicolumn{3}{|c|}{496.8 (From road to CG location) } \\
\hline Front end mass $(\mathrm{kg})$ & \multicolumn{3}{|c|}{835} & \multicolumn{3}{|c|}{835} \\
\hline Rear end mass (kg) & \multicolumn{3}{|c|}{539} & \multicolumn{3}{|c|}{539} \\
\hline Vehicle weight & \multicolumn{3}{|c|}{1374} & \multicolumn{3}{|c|}{1374} \\
\hline \multicolumn{7}{|c|}{ Suspension geometry and alignment } \\
\hline \multicolumn{7}{|c|}{ Front suspension } \\
\hline & & Left & & Right & Left & Right \\
\hline Toe angle (deg) & & -0.167 & & -0.167 & 0 & 0 \\
\hline Camber angle (deg) & & -0.33 & & -1.0 & -0.33 & -0.999 \\
\hline King pin angle (deg) & & 13.83 & & 14.16 & 13.6 & 14.16 \\
\hline Caster angle (deg) & & 2.16 & & 2.33 & 2.17 & 2.34 \\
\hline \multicolumn{7}{|c|}{ Rear suspension } \\
\hline Toe angle (deg) & & 0 & & 0.166 & 0 & 0 \\
\hline Camber angle (deg) & & -0.833 & & 0 & -0.82 & 0 \\
\hline
\end{tabular}




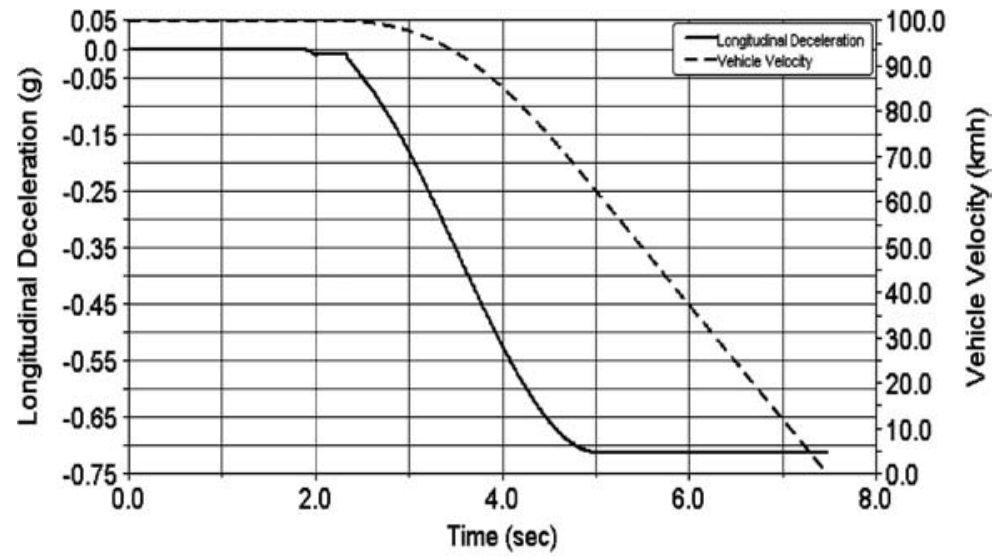

(a) - Longitudinal Deceleration and Velocity

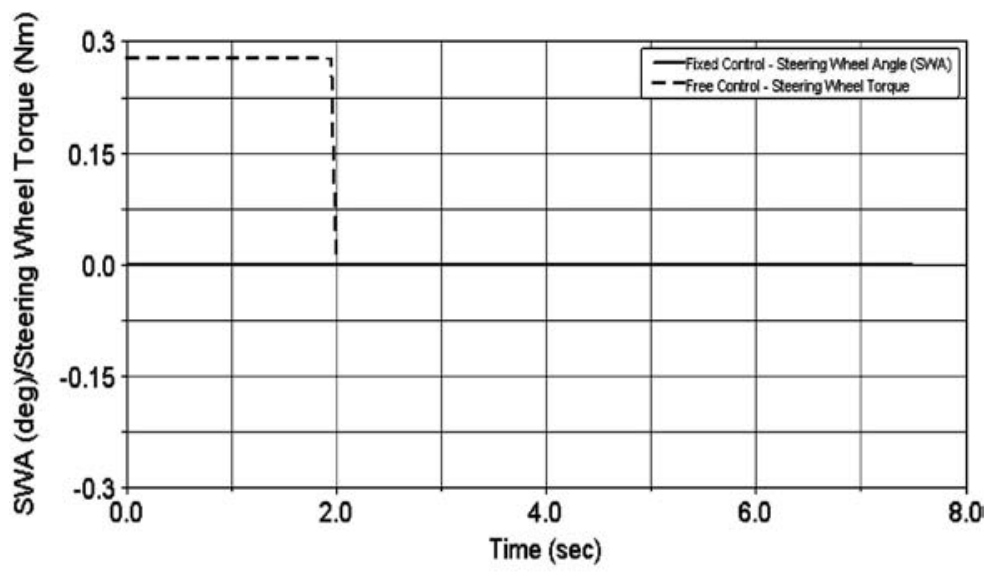

(b) - Steering Wheel Angle and Torque

Fig. 2 Longitudinal motion of the vehicle and steering control methods

of the vehicle under fixed and free control. For free control, the vehicle was driven in a straight line during a period of constant acceleration; then, the moment the brakes were applied, the steering wheel torque steadily approached zero (see Fig. 2(b)). In the case of fixed control the necessary steering torque was applied to hold the steering wheel angle fixed at an angle of zero degrees throughout the entire period of simulation.

One of the objectives was to reproduce steering drift during braking as it occurred in practice. This was measured by [5] by the amount of vehicle lateral displacement in a specified time during acceleration or deceleration. Figure 3 shows the amount of drift the vehicle experienced from the start of braking, i.e. at $2 \mathrm{~s}$ onwards. The vehicle experienced drift over approximately $3 \mathrm{~s}$ for fixed control, where it steadily moved across the carriage lane up to the point where it came to rest. The magnitude of drift from the start of braking to rest was $1.5 \mathrm{~m}$ to the left. Under free control the vehicle started to drift immediately on the start of braking (at $2 \mathrm{~s}$ ) and continued to drift to a final lateral displacement of $1.8 \mathrm{~m}$ to the left. At this point the vehicle came to rest.

\subsection{Yaw velocity}

Figure 4 compares the vehicle's predicted yaw velocity for both fixed and free control with that measured by Klaps and Day [3]. The predicted yaw velocity is positive and continuous throughout the period of braking, indicating that the vehicle was leading towards the left. Under free control, there was a sharp increase in yaw at the start of braking, which stabilized as the vehicle approached constant deceleration. This gradually decreased as the vehicle came to rest. Under fixed control the vehicle did not indicate any alteration in direction after braking was started. This changed at $2.5 \mathrm{~s}$ during the deceleration period when the vehicle started to yaw, with the maximum yaw experienced just before the vehicle came to rest. 


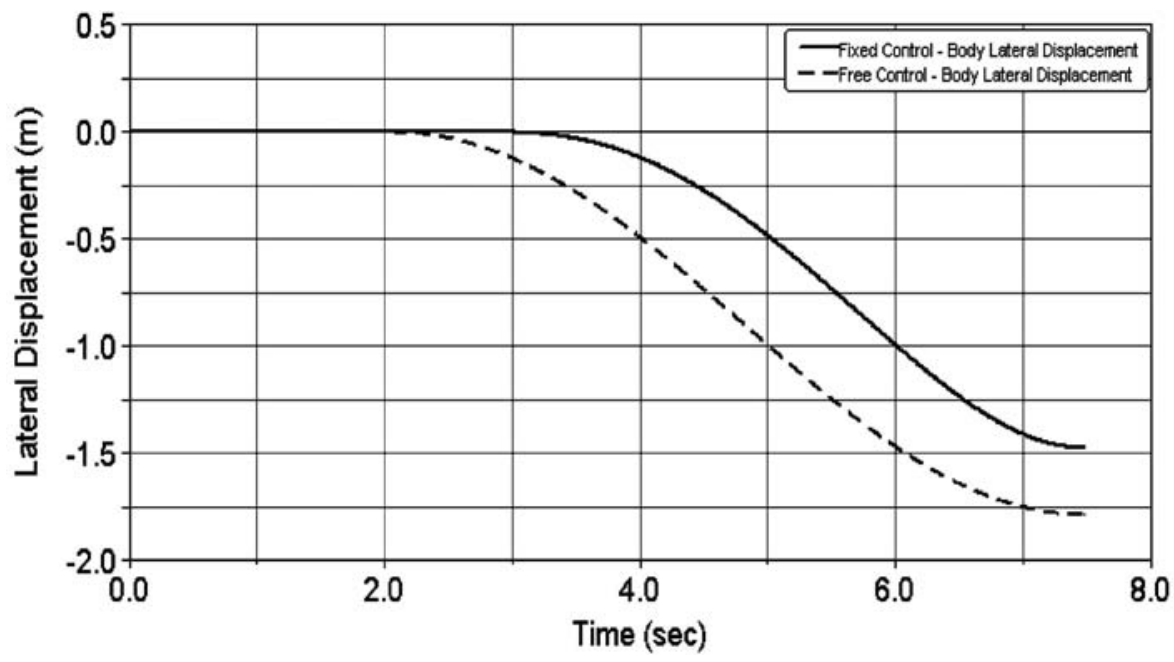

Fig. 3 Lateral displacement of the vehicle in fixed and free control method

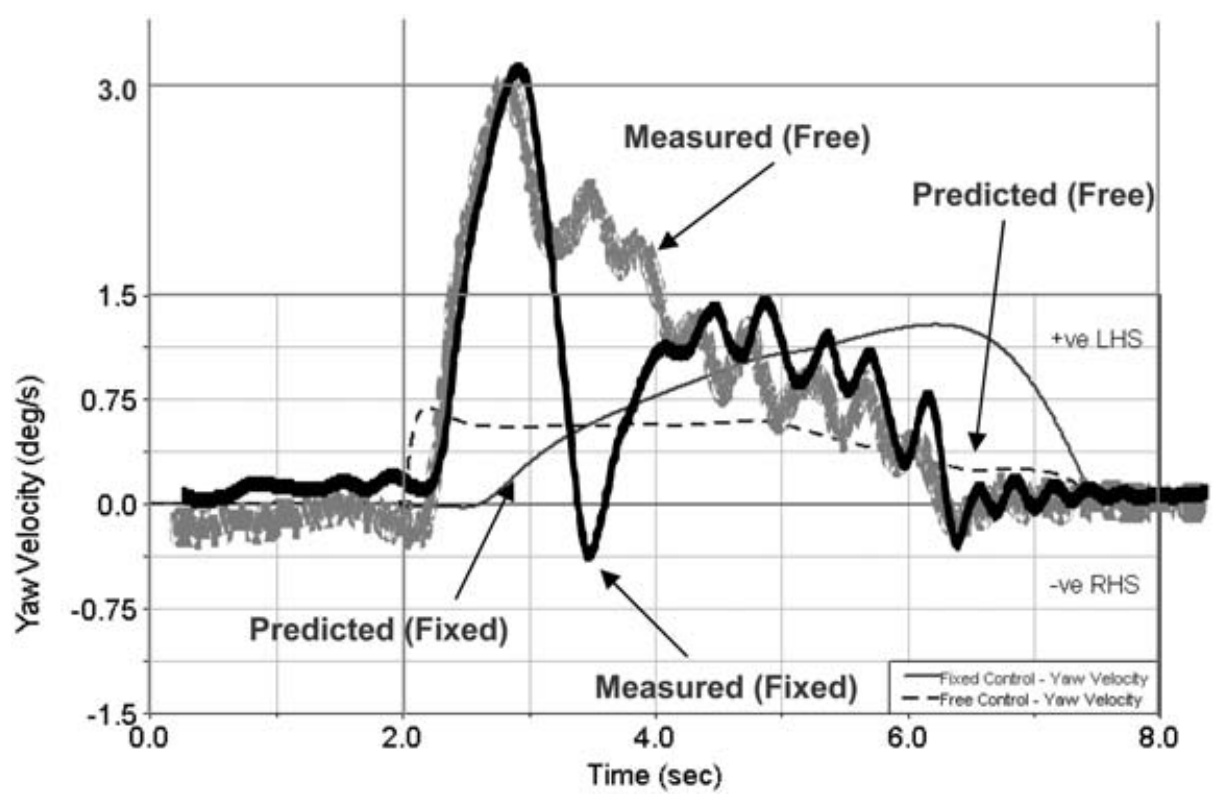

Fig. 4 Predicted and measured yaw velocity response (Klaps et al., 2004)

The experimental results of Klaps et al. [3] show some, albeit limited, agreement in the trend between predicted and experimentally measured results, ignoring the transient part (between 2-4 s) that appears in the experimental results, and which has not been identified in the model here. Further work is required to improve the correlation. The major source of difference is expected to be the assumption of inflexible suspension system components used in the simulation.

\subsection{Toe angle variation}

Figures 5 and 6 illustrate the toe angles predicted for the vehicle under fixed and free control. For static conditions the toe was set at zero; however, under dynamic conditions this changed slightly as shown in Fig. 5, owing to the drive torque applied to the front wheels. Increased toe-in improves vehicle straight-line drivability [6]. Prior to the start of braking, the toe angle was at the steady state condition. At the start of braking, the toe characteristic started to increase towards toe-out conditions for both wheels. Maximum toe-outs of $-0.86^{\circ}$ for the front left wheel and $-0.72^{\circ}$ for the right wheel were predicted. Under free control, there was an initial toe-in for the left wheel and toe-out for the right wheel. Thereafter, both wheels tended to toe-out. However, after $6 \mathrm{~s}$ the left wheel started to change orientation.

The changes occurring in toe angles for the front wheels can also be examined via tie rod forces [5], 


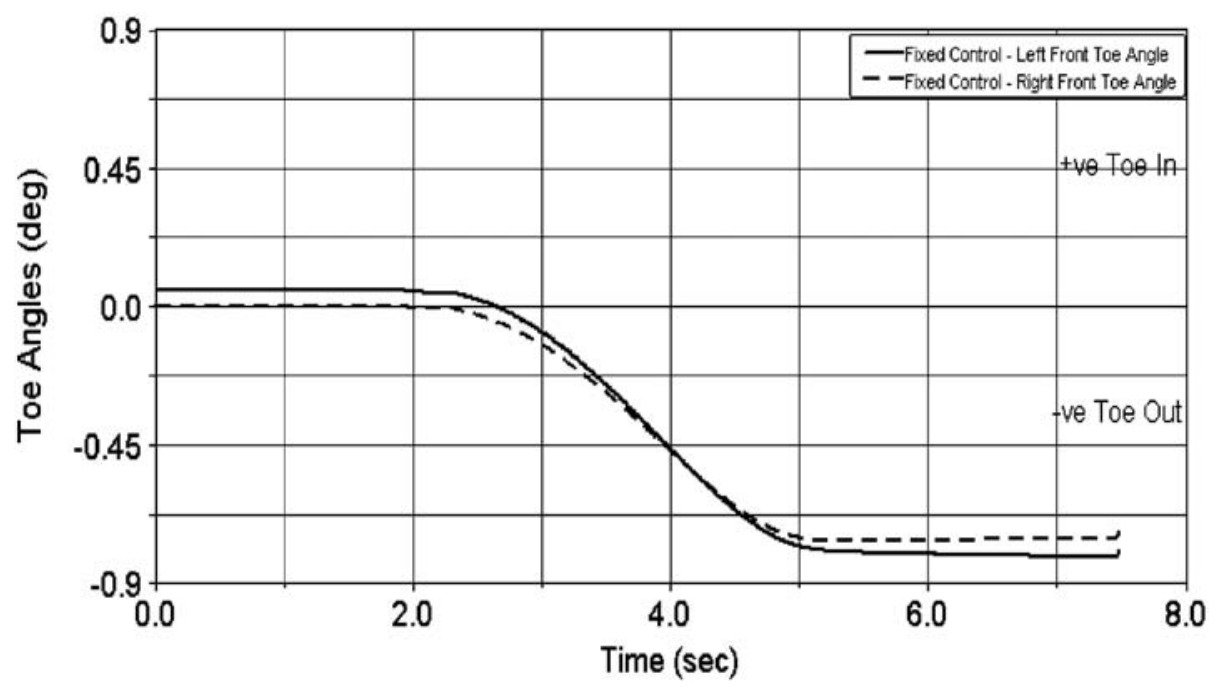

Fig. 5 Toe angles - fixed control method

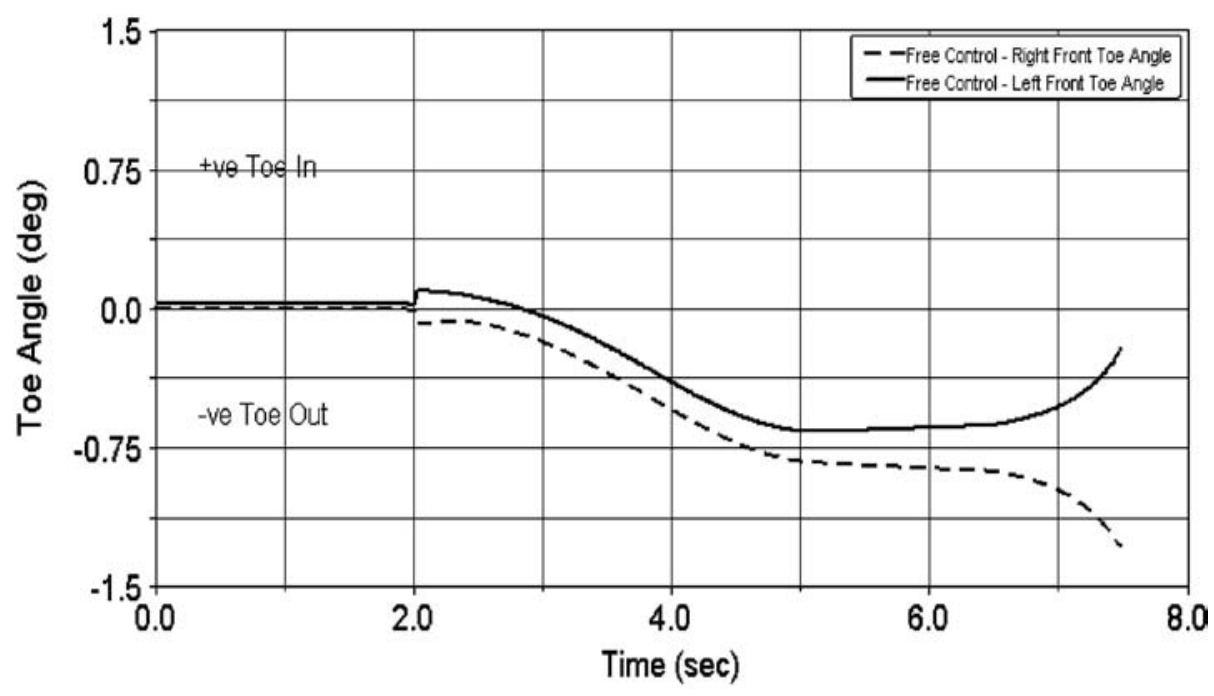

Fig. 6 Toe angles - free control method

as indicated in Fig. 7. The left tie rod experienced negative forces, indicating compression, while the right tie rod experienced positive forces, indicating tension. In the model, compression implies that the tie rod exerts a pull force on the steering arms, which steers the wheel in the toe-out direction (away from the vehicle body). For the right-hand tie rod, a positive force indicates tension, implying a push force on the steering arm causing it to move to a toein direction (towards the vehicle body). Referring to Fig. 5, the left wheel curve shows corresponding behaviour in toe change with respect to tie rod force, whereas the right wheel negates the forces applied by the tie rod by adopting a toe out position. These provide clear evidence that the steering wheel was not causing the change in wheel toe angles.
A similar explanation applies to the free control condition. Figure 8 illustrates the tie rod forces measured during free control, and under constant acceleration both the tie rods are in tension (positive - push force), indicating left and right wheel toe in orientation, since the right tie rod forces are near zero. Toe angle is also near zero, as can be observed from Fig. 6. On application of the brakes, the right tie rod experienced compressive (negative - pull) force, whereas the left tie rod experienced a slightly higher tensile (positive - push) force, indicating toe-out and toe-in for right and left wheels respectively. Figure 6 verifies this, because as the vehicle decelerates, the left tie rod is under compressive force and the right tie rod is under tensile force, thus indicating a change in the orientation of both wheels, 


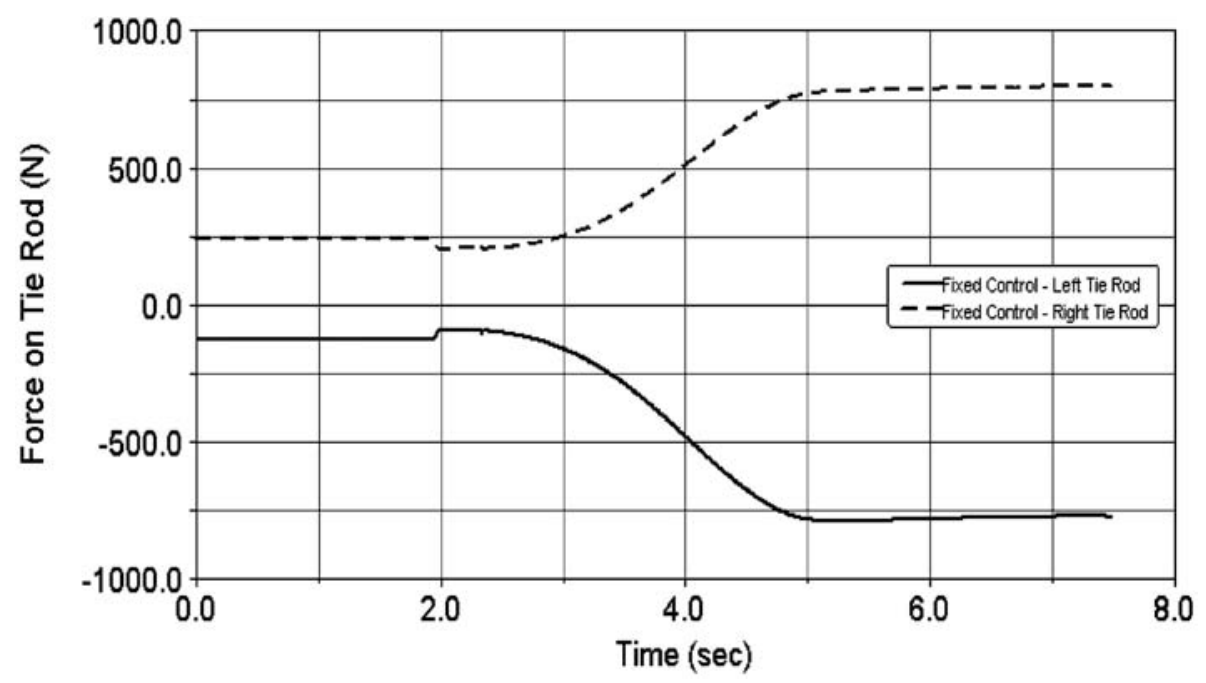

Fig. 7 Tie rod forces - fixed control method

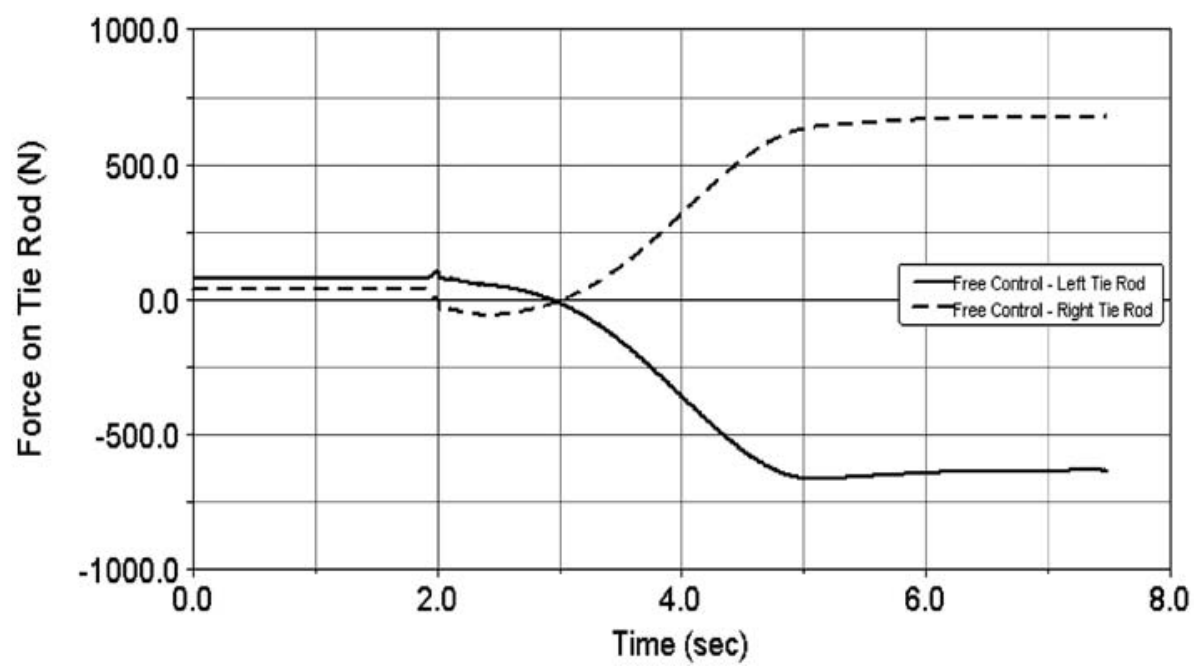

Fig. 8 Tie rod forces - free control method

left to toe-out and right to toe-in. As with the fixed control method, the right wheel negates the expected behaviour, verifying that the steering system was not imposing a change in the toe angles of the wheel.

\subsection{Caster variation}

During braking, the dynamic longitudinal weight transfer tends to lower the front and raise the rear of the vehicle; the front suspension moves into jounce and the rear suspension moves into rebound. Since the suspension is attached to the vehicle body, the change in orientation of the body to the road temporarily reduces the amount of caster during braking. This reduction in caster can bring about steering drift during braking [2].

Figures 9-10 show the caster angle variation for fixed and free control respectively. It is shown in
Fig. 9 that the caster starts to change after braking to reach a steady state condition after approximately $5 \mathrm{~s}$ of $-0.24^{\circ}$ for the left wheel, and $0^{\circ}$ for the right wheel.

With a positive caster angle, the steering swivel axis strikes the ground in front of the centre point of the tyre contact patch, creating a self-aligning torque to aid directional stability [7]. The predictions indicated that the caster angle tends to approach zero or change to a negative value, in which case the self-aligning torque from the caster is lost - this is not desirable during straight-line braking. Klaps [5] pointed out that a negative caster does not directly lead to change in steering direction (because there are other sources of self-aligning torque) but a dynamic caster change from positive to negative during braking adversely affects vehicle straight-line stability during braking. 


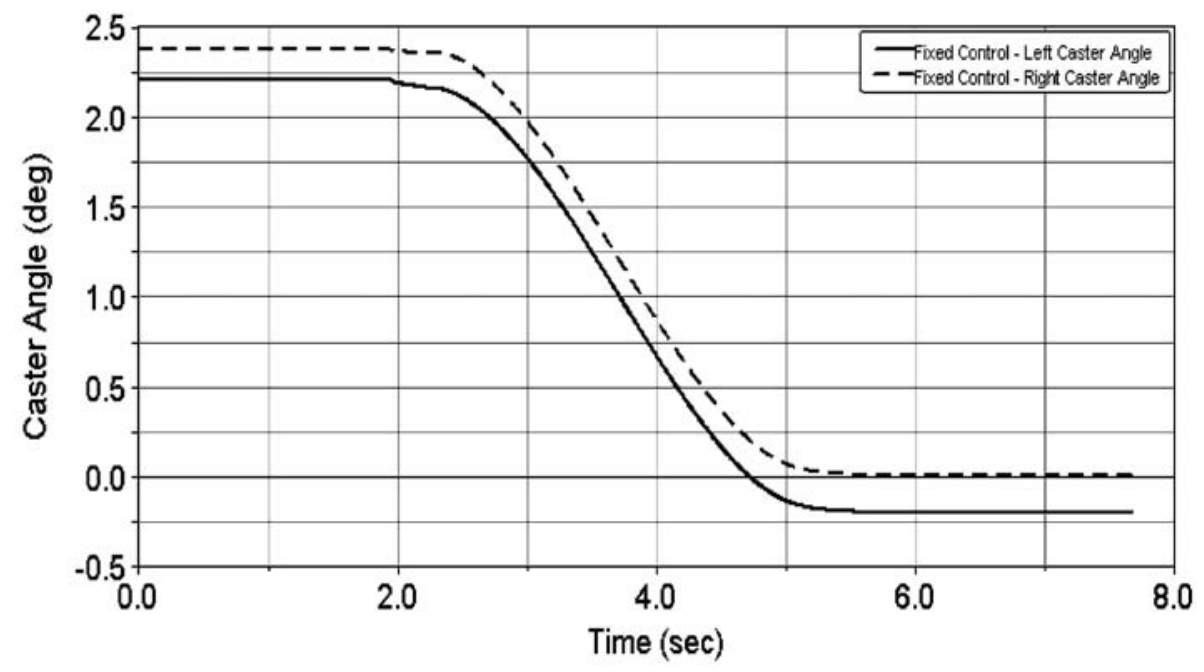

Fig. 9 Caster angle - fixed control method

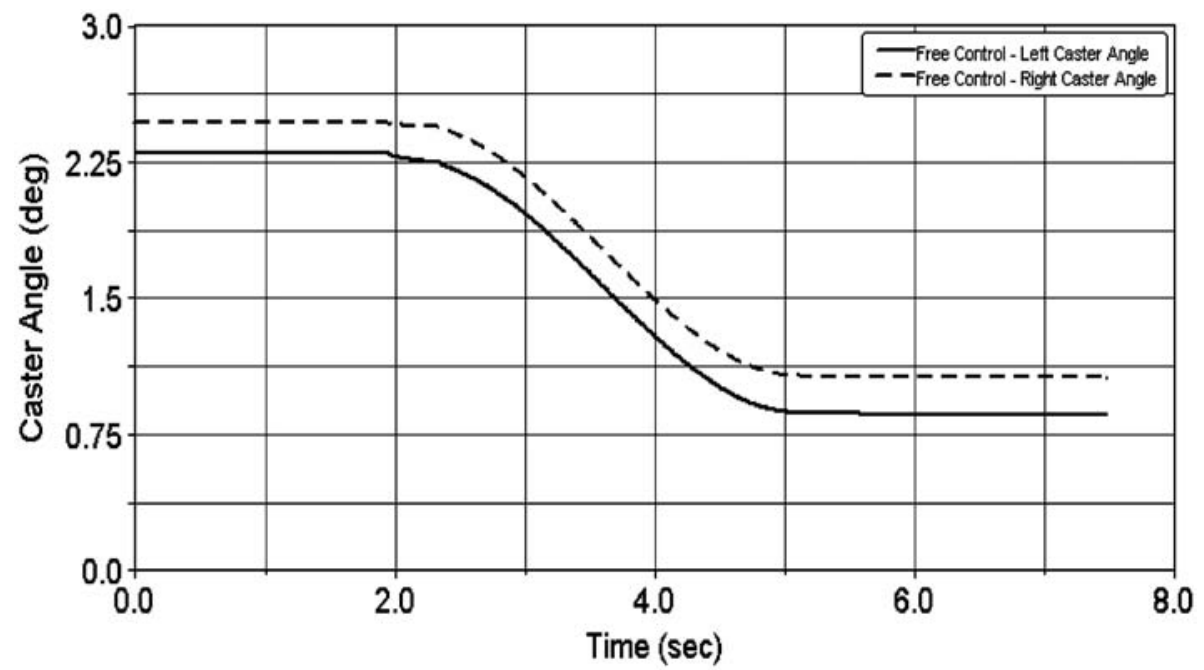

Fig. 10 Caster angle - free control method

\subsection{Sensitivity analysis}

A parameter sensitivity study was performed on the front suspension in order to determine which of the alignment settings had the greatest effect on vehicle drift. In this study there were three main suspension alignment parameters chosen, each of which related to the left and right-hand side of the front suspension, and a further two additional parameters affecting suspension compliance were also selected. For each simulation performed, one parameter was varied through three different values while the others were kept at their standard values. The same procedure was applied for the fixed and free control methods, and the effect was recorded by observing the vehicle drift.

Examination of Table 2 indicates that variation of the side-to-side suspension parameter setting might be the cause of the drift condition. Therefore, the first test was carried out by setting both the left and right suspension parameters to zero. Figure 11 shows the response for zero suspension (alignment) conditions. The magnitude of the drift was reduced by approximately $1 \mathrm{~m}$ to a value of $0.5 \mathrm{~m}$ for fixed control and $0.75 \mathrm{~m}$ for free control. It should be noted that setting camber, caster, and toe to zero reduces the drift during braking but this might have an adverse effect on the handling performance of the vehicle.

The second set of tests was carried out by varying each suspension parameter of the model in turn (the others being kept constant at their standard values) so the sensitivity of vehicle drift to each parameter could be determined. Tables 3 and 4 show the various settings used to carry out the sensitivity analysis for both fixed and free control respectively. Variation in 


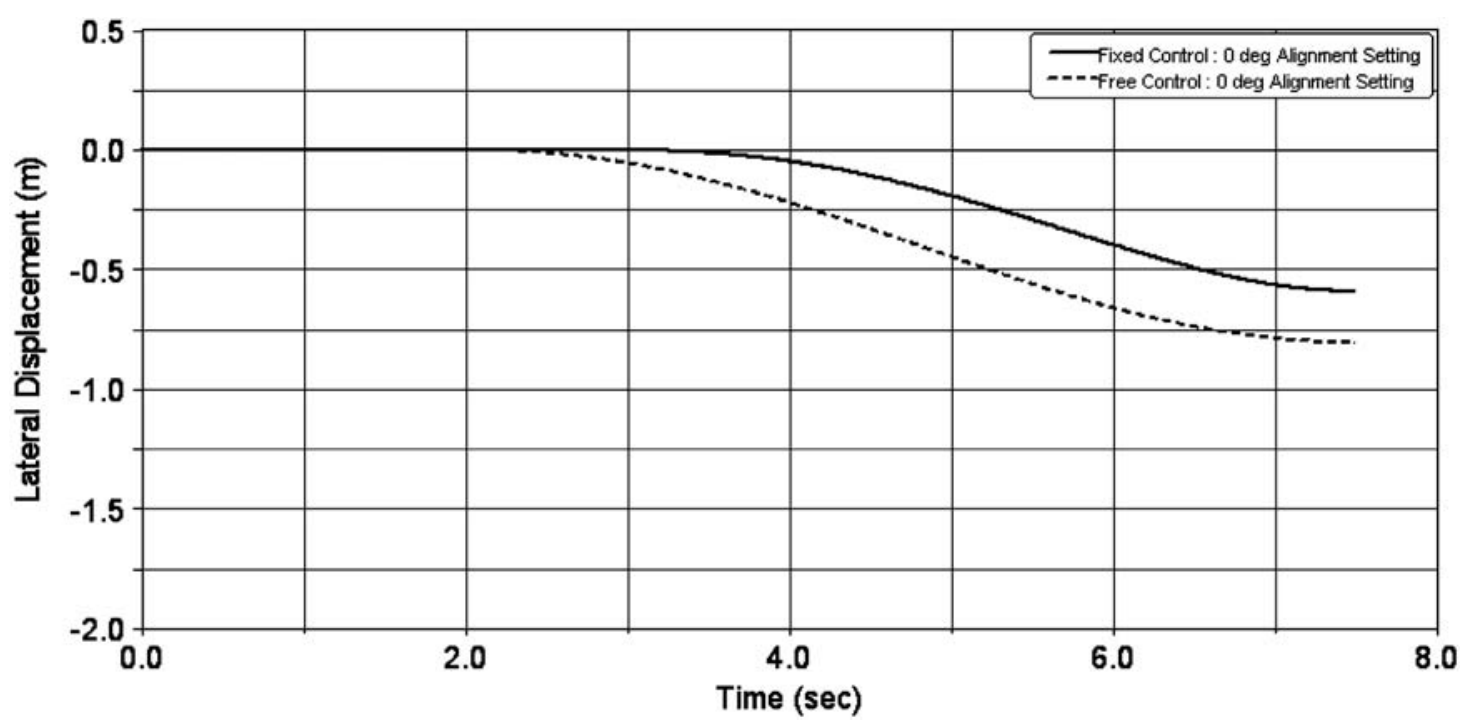

Fig. 11 Zero suspension parameters for fixed and free control

Table 3 Suspension parameter variations - fixed control (*standard value)

\begin{tabular}{|c|c|c|c|c|c|}
\hline \multicolumn{6}{|c|}{ Front suspension parameters - fixed control } \\
\hline \multicolumn{3}{|c|}{ Left } & \multicolumn{3}{|c|}{ Right } \\
\hline Parameter & Level (deg) & Vehicle drift (m) & Parameter & Level (deg) & Vehicle drift (m) \\
\hline Camber & $\begin{array}{c}-0.33^{*} \\
0 \\
0.33\end{array}$ & $\begin{array}{l}1.496 \\
1.33 \\
1.55\end{array}$ & Camber & $\begin{array}{l}-0.999 * \\
0 \\
0.999\end{array}$ & $\begin{array}{l}1.496 \\
1.36 \\
1.33\end{array}$ \\
\hline Caster & $\begin{array}{l}3 \\
0 \\
2.17^{*}\end{array}$ & $\begin{array}{l}1.41 \\
1.55 \\
1.496\end{array}$ & Caster & $\begin{array}{l}3 \\
0 \\
2.34^{*}\end{array}$ & $\begin{array}{l}1.53 \\
1.39 \\
1.496\end{array}$ \\
\hline Toe & $\begin{array}{c}-0.5 \\
0^{*} \\
0.5\end{array}$ & $\begin{array}{l}1.53 \\
1.496 \\
1.39\end{array}$ & Toe & $\begin{array}{c}-0.5 \\
0^{*} \\
0.5\end{array}$ & $\begin{array}{l}1.38 \\
1.496 \\
1.53\end{array}$ \\
\hline \multicolumn{6}{|c|}{ Lower control arm bushing } \\
\hline Parameter & & \multicolumn{3}{|c|}{ Stiffness $(\mathrm{N} / \mathrm{mm})$} & Vehicle drift (m) \\
\hline \multicolumn{2}{|c|}{ Front LCA bushing } & \multicolumn{2}{|c|}{$\begin{array}{l}3000 \\
4500 \\
5833^{*}\end{array}$} & & $\begin{array}{l}1.55 \\
1.52 \\
1.496\end{array}$ \\
\hline \multicolumn{2}{|c|}{ Rear LCA bushing } & \multicolumn{2}{|c|}{$\begin{array}{l}1400^{*} \\
1900 \\
2400\end{array}$} & & $\begin{array}{l}1.496 \\
0.88 \\
0.248\end{array}$ \\
\hline
\end{tabular}

camber angle on either side of the vehicle had a small effect on the magnitude of drift, as shown in Figs 12 (a and b). A similar effect was found by setting each wheel to a toe-in (positive) and toe-out (negative) position on either side of the front suspension. In Figs 12 (e and $\mathrm{f}$ ), toe-in on the left side reduces vehicle drift and toe-out increases the drift, whereas on the right-hand side the effect is the opposite. However, these changes in drift also had only a small effect on the magnitude of the drift for this vehicle. Similar effects were noticed in the case of the free control method, as seen in Figs 13 (a to f).

Other parameters, such as the lower control arm bushing of the front suspension, were chosen to investigate the compliance effect. These show significant changes in vehicle drift amplitude, for both fixed and free control. The front bushing of the lower control arm had a negligible effect on drift whereas 
Table 4 Suspension parameter variation - free control (*standard value)

\begin{tabular}{|c|c|c|c|c|c|}
\hline \multicolumn{6}{|c|}{ Front suspension parameters - free control } \\
\hline \multicolumn{3}{|c|}{ Left } & \multicolumn{3}{|c|}{ Right } \\
\hline Parameter & Level (deg) & Vehicle drift (m) & Parameter & Level (deg) & Vehicle drift (m) \\
\hline Camber & $\begin{array}{c}-0.33^{*} \\
0 \\
0.33\end{array}$ & $\begin{array}{l}1.79 \\
1.59 \\
1.88\end{array}$ & Camber & $\begin{array}{l}-0.999 * \\
0 \\
0.999\end{array}$ & $\begin{array}{l}1.79 \\
1.64 \\
1.7\end{array}$ \\
\hline Caster & $\begin{array}{l}3 \\
0 \\
2.17^{*}\end{array}$ & $\begin{array}{l}1.64 \\
1.66 \\
1.79\end{array}$ & Caster & $\begin{array}{l}3 \\
0 \\
2.34^{*}\end{array}$ & $\begin{array}{l}1.76 \\
1.69 \\
1.79\end{array}$ \\
\hline Toe & $\begin{array}{c}-0.5 \\
0^{*} \\
0.5\end{array}$ & $\begin{array}{l}1.94 \\
1.79 \\
1.74\end{array}$ & Toe & $\begin{array}{c}-0.5 \\
0 * \\
0.5\end{array}$ & $\begin{array}{l}1.65 \\
1.79 \\
1.89\end{array}$ \\
\hline \multicolumn{6}{|c|}{ Lower control arm bushing } \\
\hline Parameter & & \multicolumn{3}{|c|}{ Stiffness $(\mathrm{N} / \mathrm{mm})$} & Vehicle drift (m) \\
\hline \multicolumn{2}{|c|}{ Front LCA bushing } & \multicolumn{2}{|c|}{$\begin{array}{l}3000 \\
4500 \\
5833^{*}\end{array}$} & & $\begin{array}{l}1.65 \\
1.51 \\
1.79\end{array}$ \\
\hline \multicolumn{2}{|c|}{ Rear LCA bushing } & \multicolumn{2}{|l|}{$\begin{array}{l}1400^{*} \\
1900 \\
2400\end{array}$} & & $\begin{array}{l}1.79 \\
0.98 \\
0.213\end{array}$ \\
\hline
\end{tabular}

the rear lower control arm bushings had the most significant effect. In both cases of fixed and free control, an increase of 71 per cent in bushing stiffness resulted in a reduction of drift to 0.248 and $0.213 \mathrm{~m}$ respectively. From the results it is clear that the rear lower control arm bush has a significant impact on drift, though further study of the dynamics of these bushes is required to understand the resulting vehicle drift.

\section{CONCLUSIONS}

This investigation has shown that a close representation of a passenger car, used to simulate two different steering methods to investigate steering drift during braking, clearly indicates that the vehicle drifts to the left. This result has been partially verified by comparing the predicted yaw velocity of the vehicle with the measured lateral displacement. Further refinement of the model to include flexible suspension effects might be necessary to improve further the correlation between prediction and experiment.

A dynamic change of toe was predicted; the amount of toe-in or toe-out set up on a vehicle depends on the suspension compliance and desired handling characteristics. Passenger cars are generally fitted with compliant suspension bushes for reasons of isolation, causing noticeable movement when loaded. Observing the predicted toe characteristics of the front wheels under dynamic conditions indicated that the steered wheels were influenced by forces other than those induced by the steering system. In either of the steering control methods the toe angles were observed to be in 'toe-out' with the tie-rod force measured on the left side of the vehicle corresponding to the left wheel toe change. However, the right wheel toe variation was opposite with respect to the right tie rod force.

Reduction of caster angle during the braking was also predicted, which, in addition, would contribute and influence steering drift during braking. Deflection of the suspension components during braking was also predicted to cause changes in the suspension alignment, and it is concluded that, under dynamic conditions, a combination of one or more of these factors induces an alignment change in the front wheels, which then affects directional control under braking.

Finally, this research has highlighted the significance and characteristics of suspension parameters on vehicle drift. The results of the parameter sensitivity study clearly indicate that the front suspension lower control arm bush had a significant influence on lateral drift, and a more detailed study of the bushing characteristic and its influence on vehicle drift would improve still further the understanding of the causes of this phenomenon. 


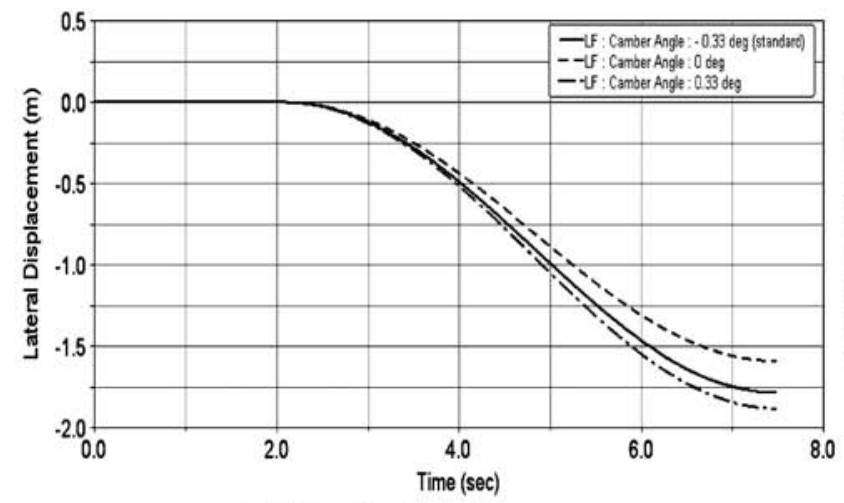

(a) Left Camber

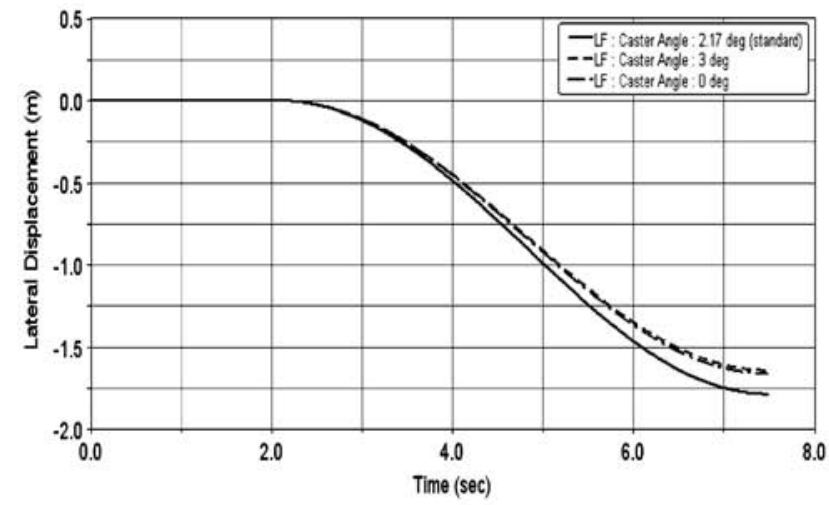

(c) Left Caster

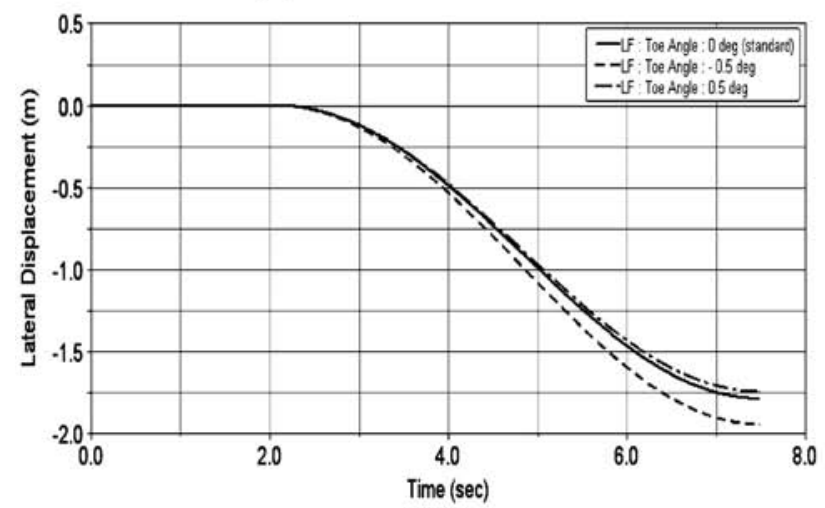

(e) Left Toe

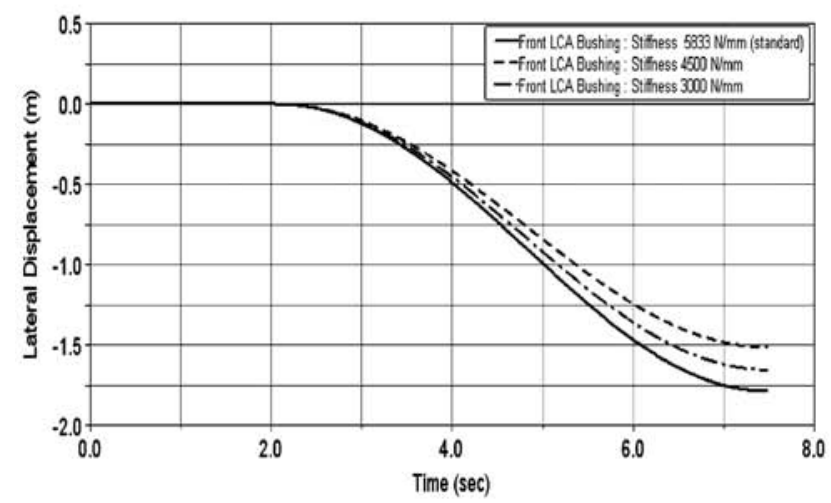

(g) Front LCA Bushing

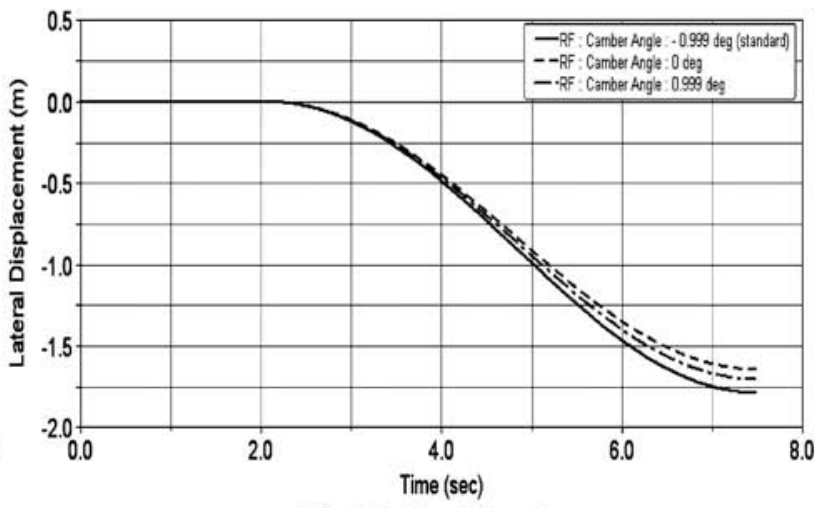

(b) Right Camber

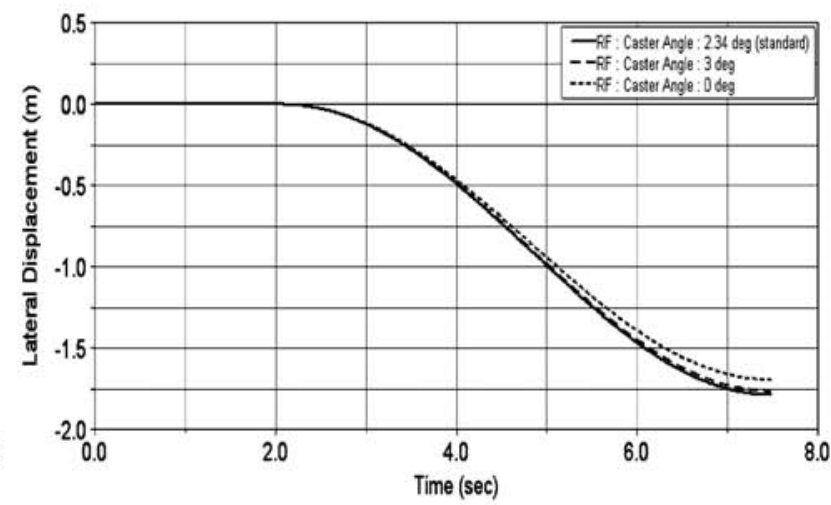

(d) Right Caster

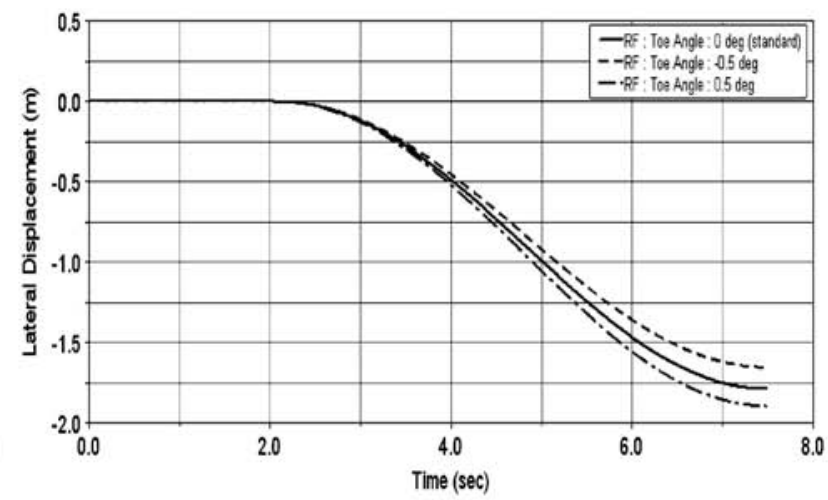

(f) Right Toe

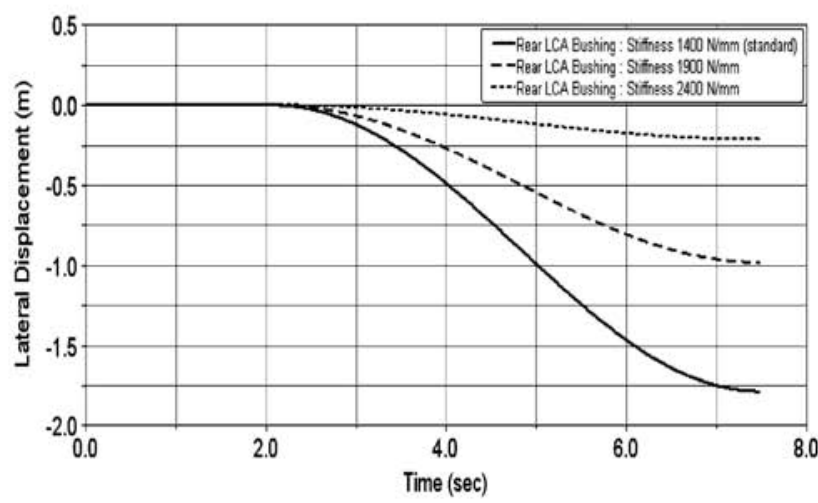

(h) Rear LCA Bushing

Fig. 12 Vehicle drift response to sensitivity parameter variation (fixed control) 


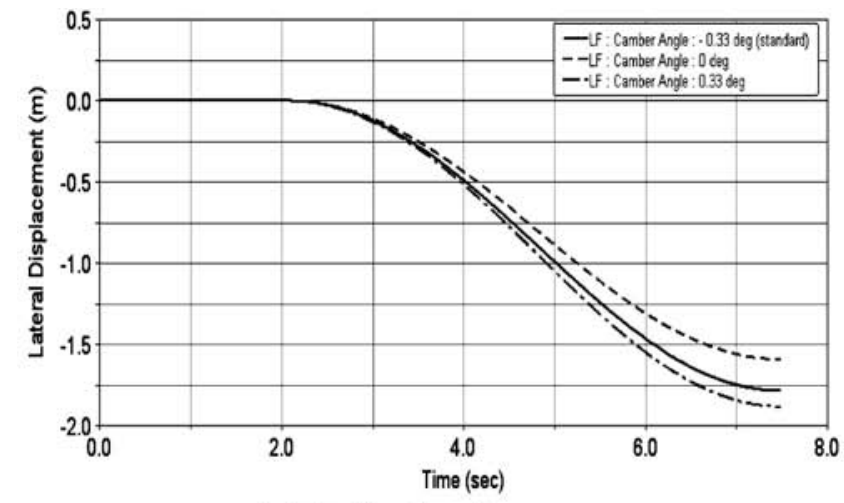

(a) Left Camber

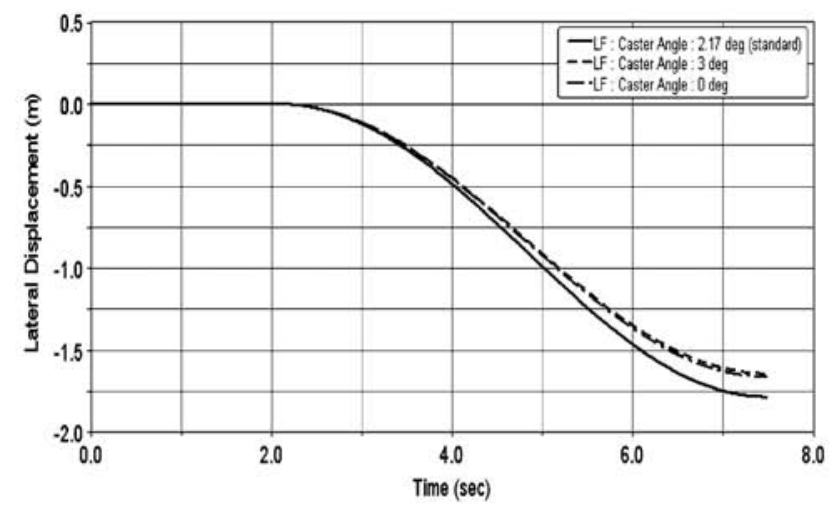

(c) Left Caster

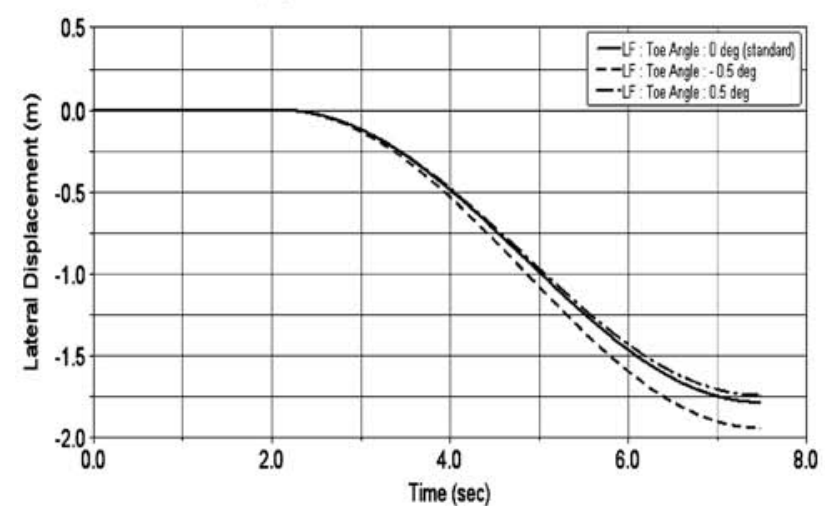

(e) Left Toe

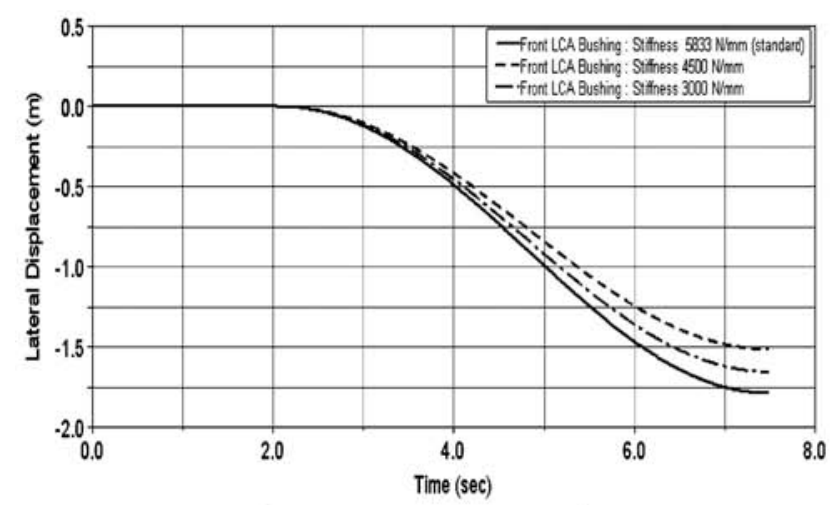

(g) Front LCA Bushing

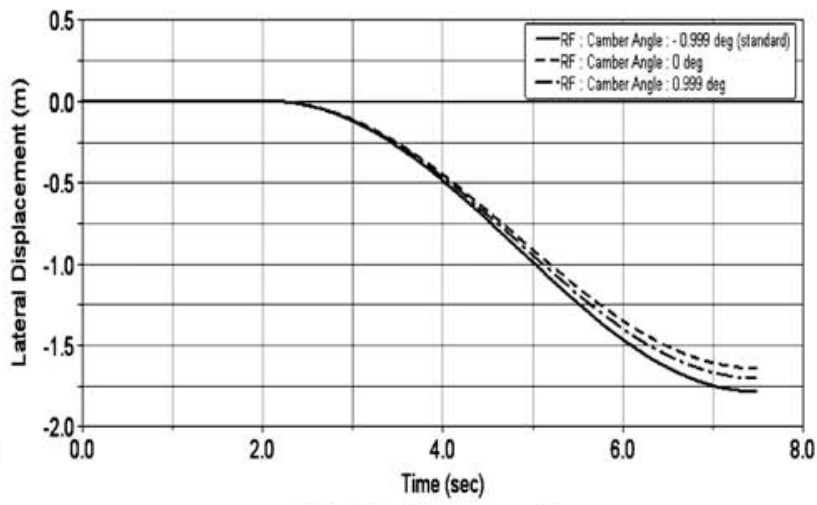

(b) Right Camber

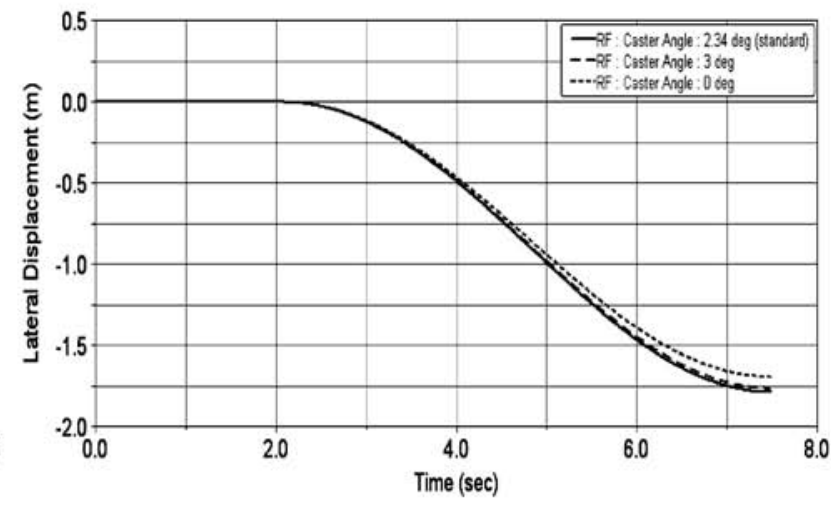

(d) Right Caster

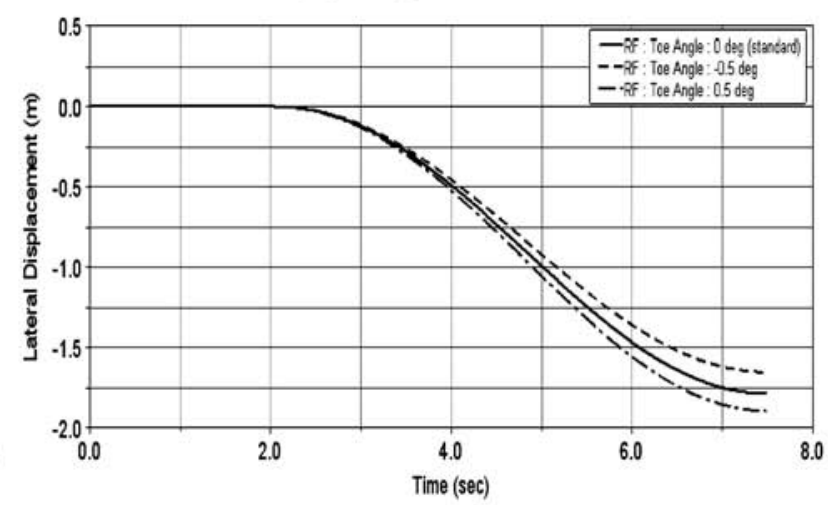

(f) Right Toe

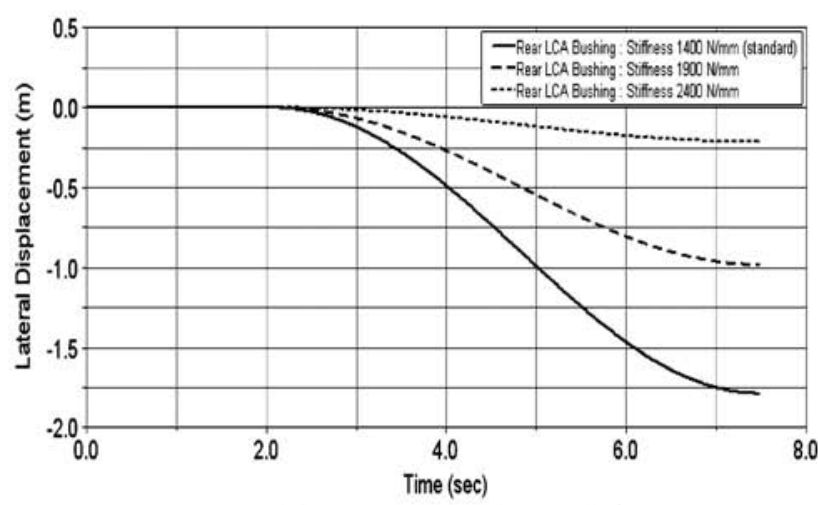

(h) Rear LCA Bushing

Fig. 13 Vehicle drift response to sensitivity parameter variation (free control) 


\section{REFERENCES}

1 MSC.ADAMS Commercial software, version 2003, 2003 (Automatic Dynamic Analysis of Mechanical Systems).

2 Klaps, J. Investigation of effects of the longitudinal stiffness of engine subframe and suspension system during straight-line braking in passenger cars. MPhil thesis, University of Bradford, 1999.

3 Klaps, J. and Day, A. J. Steering drift and wheel movement during braking: parameter sensitivity studies. IMechE, Part D: J. Automobile Engineering, 2004, 217.
4 Klaps, J. and Day, A. J. Steering drift and wheel movement during braking - static and dynamic measurements. IMechE, Part D: J. Automobile Engineering, 2005, 219(D1), 11-19.

5 Klaps, J. Braking of road vehicles 2004; steering system and tyre interactions during braking, 2004, pp. 210-242 (University of Bradford).

6 Lozia, Z. Vehicle Dynamics and Motion Simulation versus Experiment, 1998 (SAE).

7 Milliken, W. F. and Milliken, D. L. Racecar vehicle dynamics, 1995 (SAE, USA). 